\title{
General Characteristics of Mycobiota of Gray-Brown Soils Affected by Various Anthropogenic Impacts in Azerbaijan
}

\author{
E.M. Safaraliyeva* \\ Institute of Microbiology of the NAS of Azerbaijan, Baku, Azerbaijan \\ *Corresponding author
}

Key w or d s
Anthropogenic
impact, Gray-brown
soil, Mycobiota,
Specific species
Article Info
Accepted:
15 June 2019
Available Online:
10 July 2019

A B S T R A C T
In the presented work, the mycobiota of gray-brown soils of the Absheron Peninsula of the Azerbaijan Republic differing by the nature of the anthropogenic effect were characterized by the species composition and were definite that 81 species of real fungi (Mycota) involved in the formation of studied areas. Became clear that, in all cases, anthropogenic impacts causes to decrease the species composition of the myco-variety compare with relative clear soil and this situation the highest level meets in soils contaminated with oil. Nevertheless, in the formation of mycobiota of each area along with common species, is also participates specific species, which their number for separate biotopes varies between 4-7 species that is, any area investigated by anthropogenic impacts is characterized by a microcomplex, in some sense carrying specificity sign.

\section{Introduction}

The intensification of production processes according to the growing number of people in the world also causes increase both anthropogenic impacts $(10,13)$, as well as the technogenic load to the environment, which as a form of manifestation causes to the pollution of environmental, increase of illness due to the degradation of the environment and so on (2). All of these make unavoidable the global environmental problems, which solving such problems is one of the most important research directions of the modern era (14), at least because the negative side of this problem touches everyone. For this reason, studies carried out in this direction first implements the assessment of the general condition of one or another ecosystem and for this reason, are used different approaches (15).

Assessment of the status of any ecosystem by anthropogenic and technogenic impact load is implemented based on a number of indicators which, to use microorganisms of soil, primarily of fungi is one of the interesting facts of studies conducted in this direction (1, 14). So that, fungi differ from other microorganisms of soil by the quality like as their ecological functions, the amount of biomass 
formed in the soil, an active role in the formation of soil fertility and phytosanitary status, etc. In other word, fungi are an integral component of biogeocenoses, actively participates in biosphere substances and energy circulation, has a significant impact on the productivity of both the soil and cultivated plants (11).

As the microorganisms of the soil are different by the number of composition, species diversity, the nature of their ecological functions that they carry out their level of learning is also not the same (4) and today the research of fungi, especially those living in anthropogenically affected biotopes, is not at the desired level. The first step in this issue is more advisable to start from the characterization of species composition of mycobiota of this or that area. So that, for the understand the essence of any process, first of all, it is necessary to clearly identify its participants.

Therefore, the purpose of the presented work was dedicated to the assessment by the species composition of fungi biotas on the same type of soil affected by various characteristic anthropogenic effects.

\section{Materials and Methods}

The research was carried out in gray-brown soil type of Absheron peninsula. For this reason, samples were taken from the areas which irrigated, contaminated with oil and oil products, subjected to motor vehicle contamination, used for the dump and relatively clean soils (as a control), as well as from the city soils and were evaluated by the species composition of mycobiota(7-8). In the sampling process, were used from stationary experience areas, for this purpose, everywhere has been selected areas with 100x100m and samples were taken from 10 territories of every those area. The processing of taken sampling was carried out at the microbiological biotechnology laboratory of the Institute of Microbiology of the National Academy of Sciences of Azerbaijan.

For the taking fungi to the pure cultures, as a nutritious medium were used from malt juice agar (MJA), rice agar (RA), starchy (SA) and potato agar (PA), Chapek, Chapek agar (CA). Preparation, sterilization and to pour of medium to the Petri dishes were performed according to known methods (3) in microbiology.

The identification of pure cultures of fungi obtained in laboratory conditions was carried out on the basis of $(5,9,12)$ suitable determinants. The naming of fungi was carried out in accordance with the principles and approaches to the international nomenclature (6).

\section{Results and Discussion}

The biosphere is one of the places where both biodiversity and nutrition a global ecosystem. Territories of many large cities are exposed to various degradation (construction of production facilities on the area near people's settlements, disposal of waste in the environment without being sure of their safety, collapse of the gases emitted by the motor transport first into the air and then into the ground, the construction of high-rise buildings, etc.) as a result of the spontaneous use of humans by nature. This, in turn, leads to the collection of heavy metals and other substances in the soil, as a result, causes the destruction of the vegetation cover therein, the change in the structure of the natural biota of the soil, and formation of the new biota. This type of technogenic impact also contributes to the formation of specific microbiota in soil biota. For this reason, firstly was analyzed the mycobiota of the selected areas by the species composition. Became clear that, from the 800 
samples taken from the areas of the same type of soil which has been exposed to 7 different anthropogenic effects identified about 81 species of fungi belongs to the true fungi (Mycota), which their taxonomic structure is summarized in table 1. As seen, $12,3 \%$ of registered fungi belong to the division of Zygomycota and the remaining $87,7 \%$ to the Ascomycota.

As is known, sac fungi divided into 2 part anamorphic and telemorphic (12). During describing 71 species of sac fungi registered in research from these aspects became clear that most of them belong to the anamorphs, those that do not have a sexual reproductive stage.

Thus, $92,6 \%$ of the registered fungi belong to anamorphs and $7,4 \%$ to teleomorphs. It should be noted that registration majority of sac fungi belonging to anamorphs in this or another biotope are the facts that have been confirmed in many worldwide mycological studies in the world as well as in Azerbaijan. This is due to the fact that the number of species of these fungi is much higher and cosmopolitan than that of other taxonomic groups.

When characterizing the recorded fungi by the number of species, becomes clear that, with the least number are characterized division of Zygomycota with the genuses of Absida, Actinomucor, Mortierella, Circinella, but genuses like as Aureobasidium, Botryotrichum, Botrytis, Cephalotrichum, Humicola, Myrothecium, Trichocladium, Stachybotrys, Gliocladium, Acremonium, Trichothecium, Paecilomyces, Talaromyces, Thysanophora, Ulocladium, Coniothyrium, Torula, Epicoccum, Aureobasidium, Candida, Geotrichum, Gliomastix, Sordaria, Torula from the division of Ascomycota are characterized by one species and the rest divisions by 2 to 14 species. With most species are characterized genus of Penicillium, which is represented by 14 species in the formation of mycobiota of the studied soils. Aspergillus, Trichoderma Mucor and Fusarium genus are also represented with many species which vary between 2-7. In general, the number of such species is 25 .

From the results about to the spread of these fungi recorded on separate anthropogenic impacts areas, became clear that in all cases the number of registered fungi species decreases compare with species composition of the myco-variety inherent to the relative clear soil (Table 2).

So, if we group the registered fungi by contamination sources, as it is seen from the table 2, compared to relatively clean soils, the most genus of fungi was found irrigated soils, where 21 genus join in itself 47 species of fungi. Second place was the area used as dump where 20 genus was represented with 42 species, in the $3^{\text {rd }}$ urban lands where 16 genus was represented with 37 species, $4^{\text {th }}$ polluted area and 15 genus with 39 species, 5th area polluted by the impact of motor transport and 34 species from the 14 genus found on the plants planted there, and lastly 12 genus with 26 species in the areas where were polluted with oil and oil products. In other words, the anthropogenic impact is, in any case, characterized as a factor causing to the scarcity of species diversity and this situation at the higher level exposed itself in the lands polluted with oil and oil products.

Although in all cases by the anthropogenic impact the species composition of mycobiota is scanty, but in addition with general species involved in the formation of each area are also participates specific species, and their number varies from 4 to 7 depending on biotopes that is, each area investigated by the anthropogenic impacts is characterized by a micro-complex, which in some sense has a specificity sign. 
Table.1 Taxonomic structure of registered fungi

\begin{tabular}{|c|c|c|c|c|}
\hline $\begin{array}{l}\text { Divisio } \\
\mathrm{n}\end{array}$ & Class & Order & Family & Genus (species) \\
\hline \multirow[t]{2}{*}{$\begin{array}{l}\text { Zygo- } \\
\text { mycota }\end{array}$} & \multirow[t]{2}{*}{$\begin{array}{l}\text { Zygo- } \\
\text { mycetes }\end{array}$} & \multirow[t]{2}{*}{ Mucorales } & Mucoraceae & $\begin{array}{l}\text { Absida(1), Mucor(4), Rhisobus(2), } \\
\text { Actinomucor(1), Mortierella(1) }\end{array}$ \\
\hline & & & Lichtheimiaceae & Circinella(1) \\
\hline \multirow{23}{*}{$\begin{array}{l}\text { Asco- } \\
\text { mycota }\end{array}$} & \multirow{2}{*}{$\begin{array}{l}\text { Leotio- } \\
\text { mycetes }\end{array}$} & Helotiales & Sclerotiniaceae & Botrytis(1) \\
\hline & & Erysiphales & Erysiphaceae & Sphaerotheca(1) \\
\hline & \multirow[t]{3}{*}{$\begin{array}{l}\text { Eurotio- } \\
\text { mycetes }\end{array}$} & Eurotiales & Trichocomaceae & $\begin{array}{l}\text { Aspergillus(7), Penicillium(14) } \\
\text { Paecilomyces(1),Talaromyces(1) } \\
\text { Thysanophora(1) }\end{array}$ \\
\hline & & \multirow[t]{2}{*}{ Onygenales } & Onygenaceae & Chrysosporium(1) \\
\hline & & & Arthrodermataceae & Trichophyton(1) \\
\hline & $\begin{array}{l}\text { Orbilio- } \\
\text { mycetes }\end{array}$ & Orbiliales & Orbiliaceae & Arthrobotrys(1) \\
\hline & \multirow{10}{*}{$\begin{array}{l}\text { Sordario } \\
- \\
\text { mycetes }\end{array}$} & \multirow[t]{4}{*}{ Hypocreales } & Nectriaceae & Fusarium(4),Cylindrocarpon(1) \\
\hline & & & Hypocreaceae & $\begin{array}{l}\text { Trichoderma(5), Stachybotrys(1) } \\
\text { Gliocladium(1), Acremonium(1) } \\
\text { Trichothecium(1) }\end{array}$ \\
\hline & & & Stachybotryaceae & Myrothecium(1) \\
\hline & & & Bionectriaceae & Gliomastix(1) \\
\hline & & \multirow[t]{3}{*}{ Sordariales } & Plectosphaerellaceae & Verticillium(2) \\
\hline & & & Sordariaceae & Sordaria $(1)$ \\
\hline & & & Chaetomiaceae & $\begin{array}{l}\text { Botryotrichum }(1), \text { Chaetomium }(2) \\
\text { Humicola }(1), \text { Trichocladium }(1)\end{array}$ \\
\hline & & $\begin{array}{l}\text { Ophiosto- } \\
\text { matales }\end{array}$ & Ophiostomataceae & Sporothrix(2) \\
\hline & & Capnodiales & Davidiellaceae & Cladosporium(3) \\
\hline & & Microascales & Microascaceae & Cephalotrichum(1), Scopulariopsis(2) \\
\hline & \multirow{5}{*}{$\begin{array}{l}\text { Dothide } \\
\text { o- } \\
\text { mycetes }\end{array}$} & \multirow[t]{4}{*}{ Pleospo-rales } & Pleosporaceae & Alternaria(2), Phoma(2), Ulocladium(1) \\
\hline & & & Leptosphaeriaceae & Coniothyrium(1) \\
\hline & & & Torulaceae & Torula(1) \\
\hline & & & Didymellaceae & Eрісоссит (1) \\
\hline & & Dothideales & Dothioraceae & Aureobasidium(1) \\
\hline & \multirow{2}{*}{$\begin{array}{l}\text { Sacchar } \\
\text { o- } \\
\text { mycetes }\end{array}$} & \multirow{2}{*}{$\begin{array}{l}\text { Saccharomyc } \\
\text { etales }\end{array}$} & Saccharomycetaceae & Candida(1) \\
\hline & & & Dipodascaceae & Geotrichum(1) \\
\hline
\end{tabular}


Table.2 Number characteristics of the registered fungi distributed of various anthropogenic affected soils

\begin{tabular}{|l|c|c|c|c|c|}
\hline \multirow{2}{*}{ Contamination sources } & \multicolumn{5}{|c|}{ Distribution of fungi on taxons } \\
\cline { 2 - 6 } & Division & Class & Order & Family & $\begin{array}{l}\text { Genus } \\
\text { (species) }\end{array}$ \\
\hline $\begin{array}{l}\text { Contaminated with the } \\
\text { products of manufacture }\end{array}$ & 3 & 4 & 5 & 8 & $22(39)$ \\
\hline Irrigated soils & 3 & 5 & 7 & 12 & $21(47)$ \\
\hline Oil and oil products & 3 & 4 & 5 & 8 & $17(26)$ \\
\hline $\begin{array}{l}\text { Soil polluted by the impact of } \\
\text { motor transport and plants } \\
\text { planted there }\end{array}$ & 3 & 4 & 5 & 8 & $18(34)$ \\
\hline Urban soils & & & & & \\
\hline Areas used for dump & 3 & 4 & 5 & 8 & $16(37)$ \\
\hline Relatively clean soils & 3 & 4 & 6 & 11 & $21(42)$ \\
\hline Total & 3 & 6 & 9 & 16 & $25(51)$ \\
\hline
\end{tabular}

Which is also evidences by the following information.

As mentioned above, in the mycobiota of each studied area has observed a certain specificity sign which is related to participation combination of species involved in the formation of their mycobiota.

More precisely, there are some species that they participate only in the formation of a mycobiota of the soil of fields. These species are consists of the following.

In the formation of mycobiota of gray-brown soils exposed to contamination by manufacture products involves three species: Absida caerulea, Thysanophora penicillioides and Ulocladium atrum. In the irrigated soils the number of such species is equivalent to 2, which consists of species such as Epicoccum nigrum and Sporothrix fungorum.

But in research the species like as Humicola gricea, Torula herbarum, and Verticillium alboatrum were only presence in formation of mycobiota of soils contaminated with oil and oil products.
Species like as Botryotrichum piluliferum, Myrothecium roridum and Scopulariopsis brevicaulis involved in the formation of specific mycobiota of areas contaminated from the impact of auto transport and plants plated there. The number of specific species on urban mycobiota is equal to 4 , and they consisting of fungi such as Acremonium atrogriseum, Gliomastix, Talaromyces rugulosus and Trichophyton terrestre.

Only the number of species participating in the formation of mycobiota of dump is equal to 3 and for this content includes species like as Coniothyrium olivaceum, Geotrichum candidum and Trichocladium polysporum.

Most species participates in the formation of mycobiota are on the relatively clean soils and their number in these soil is equal to 7 , they consisting of species like as Actinomucor elegans, Alternaria chlamydospora, Chaetomium cellulolyticum, Chrysosporinum merdanum, Gliocladium roseum, Trichoderma hamatum and T. harzianum

Thus, from the carried out of research became clear that 81 species of fungi are involved in 
the formation of mycobiota of gray-brown soils of Absheron Peninsula of the Republic of Azerbaijan which was differed by the nature of the anthropogenic impact. It has been shown that the number of fungi species registered in all cases decreases according by the species composition of myco diversity peculiar to relative clear soil and it gives itself the highest level on the soil contaminated with oil. Nevertheless, in the formation of mycobiota of each area along with common species, is also participates specific species, and their number for separate biotopes varies between 4-7 species. So that, each researched area subject to the anthropogenic impacts is characterized by a micro-complex, in some sense carrying specificity sign.

\section{References}

1. Devetter $M$, Háněl L, Řeháková $K$, Doležal J. 2017. Diversity and feeding strategies of soil microfauna along elevation gradients in Himalayan cold deserts. PLoS ONE 12(11): e0187646. https://doi.org/10.1371/journal.pone.018 7646

2. Evdokimova G.A., Korneykova M.V., Lebedeva E.V. 2013. Complexes of potentially pathogenic microscopic fungi in anthropogenic polluted soils. J Environ Sci Health A Tox Hazard Subst Environ Eng., 48(7):746-52. doi: 10.1080/10934529.2013.744615.

3. Handbook of Mycological Methods. http://www.fao.org/fileadmin/user_uplo ad/agns/pdf/coffee/Annex-F.2.pdf

4. Hujslova M., Kubatova A., Cudickova M., Kolarik M. 2010. Diversity of fungal communities in saline and acidic soils in the Soos National Natural Reserve, Czech Republic // Mycological Progress, 10:1-15. http://www.ascofrance.fr/uploads/forum _file/Humber-RA-Chapter-VEntomofungi-identification-0001.PDF
5. http://www.mycobank.org/MycoTaxo.a spx

6. Jennifer L.K., Lee A., Hart M., Moutoglis P., John N., Trevors J.T. 2006. Methods of studying soil microbial diversity//Biochemistry, $15: 87-88$.

7. Kirk J.L., Beaudette L.A., Hart M., Moutoglis P., Klironomos J.N., Lee H., Trevors J.T. 2004. Methods of studying soil microbial diversity., 58(2):169-

88.DOI:10.1016/j.mimet.2004.04.006

8. Kirk P. M., Cannon P. F., Minter D. W. Stalpers J.A. (2008). Dictionary of the fungi, 10th edn. CABI publishing. Wallingford (UK), 600.

9. Korneykova M.V., Lebedeva E.V. 2018. Opportunistic Fungi In The Polluted Soils Of Kola Peninsula. Geography, Environment, Sustainability, Vol.11, No 2, p. 125-137 DOI-10.24057/2071-9388-2018-11-2125-13

10. Mohamed A. Abdel-Sater, Abdel-Aal H. Moubasher, Zeinab S.M. Soliman. 2016. Diversity of filamentous and yeast fungi in soil of citrus and grapevine plantations in the Assiut region, Egypt. Czech Mycology 68(2): 183-214,

11. Satton D., Fothergill A., Rinaldi M. (2001). Determinant of pathogenic and conditionally pathogenic fungi. $\mathrm{M}$ : World, 486.

12. Steffan J. J., Brevik E. C., Burgess L. C.Cerdà A. The effect of soil on human health: an overview. European Journal of Soil Science, January 2018,69, 159171

13. Teillard F., Anton A., Dumont B., Finn J.A., Henry B. et al., 2016. A review of indicators and methods to assess biodiversity - Application to livestock production at global scale. Livestock Environmental Assessment and 
Performance (LEAP) Partnership. FAO, Rome, Italy. http://www.fao.org/3/aav151e.pdf

14. Terekhova V., Ashikhmina T. 2013. Biodiagnostics in the environmental assessment of soils and adjacent environments. Theoretical and Applied Ecology, 1:107-108.
15 Vlasov D.Y., Abakumov E.V.,
Tomashunas V.M., Krylenkov V.A.,
Zelenskaya M.S. 2014. Mycobiota of
soil and anthropogenic substrates of the
Yamal Peninsula. Gig Sanit., 5:49-51.

\section{How to cite this article:}

Safaraliyeva, E.M. 2019. General Characteristics of Mycobiota of Gray-Brown Soils Affected by Various Anthropogenic Impacts in Azerbaijan. Int.J.Curr.Microbiol.App.Sci. 8(07): 17121718. doi: https://doi.org/10.20546/ijcmas.2019.807.203 